\title{
Acesso à Justiça para Mulheres em Situação de Violência Análise da Atuação da Delegacia da Mulher à Luz da Justiça Social Pautada na Ética da Alteridade e na Responsabilidade
}

\author{
Tatiana Mareto Silva \\ Doutora vinculada ao Programa de Pós-Graduação Strictu Sensu em Direitos e Garantias Fundamentais da Faculdade \\ de Direito de Vitória - FDV. Mestre em Políticas Públicas e Processo pela Faculdade de Direito de Campos - FDC (2007). \\ Especialista em Direito Processual Civil pela Faculdade de Direito de Vitória - FDV (2004).tmareto@gmail.com \\ Aloísio Krohling \\ Pós-doutor em Filosofia Política pelo Instituto Santo Anselmo em Roma, Itália. Mestre em Filosofia e Teologia \\ pela Universidade Gregoriana em Roma, Itália. Graduado em Filosofia pela Faculdade Anchieta, São Paulo. Graduado em \\ Ciências Sociais pela Loyola University, Chicago, USA. krohling@gmail.com
}

A Lei Maria da Penha (Lei 11.340), de 2006, publicada há 10 anos, provavelmente não representou a redução da violência doméstica e sexual contra a mulher. Os mecanismos existentes antes da referida lei também não foram eficientes para reduzir os casos de violência de gênero no Brasil. $O$ estudo analisou as delegacias especializadas em violência contra a mulher para verificar se sua atuação condiz com a base teórica que sustenta os tratados internacionais e documentos ratificados pelo Brasil para a erradicação da violência contra a mulher, utilizando as teorias da justiça social de Emmanuel Lévinas, da ética da responsabilidade e da alteridade, e de Nancy Fraser, com sua visão tridimensional das políticas públicas de gênero, pela metodologia do múltiplo dialético, concluindo pela necessidade de um repensar a execução das delegacias especializadas para que representem um acesso à justiça real e ético.

Palavras-chave: Violência contra a mulher. Ética. Justiça social. Delegacia de proteção à mulher.

\section{ACCESS TO JUSTICE TO WOMEN VICTIM OF VIOLENCE: ANALYSIS OF WOMEN'S SPECIAL POLICE STATION ACTING AT LIGHT OF SOCIAL JUSTICE BASED ON ALTERITY ETHICS AND RESPONSABILITY}

\section{ABSTRACT}

Law 11.340/2006, Lei Maria da Penha, published 10 years ago, may did not represent the reduction of domestic and sexual violence against women. The mechanisms that existed prior to this law were also not effective in reducing cases of gender violence in Brazil. The study analyzed the specialized police stations in violence against women to verify if their action is consistent with the theoretical basis that supports the international treaties and documents ratified by Brazil for the eradication of violence against women, using the theories of social justice of Emmanuel Lévinas, The ethics of responsibility and alterity, and Nancy Fraser, with her three-dimensional vision of the public policies of gender, by the methodology of the dialectical multiple, concluding on the need to rethink the execution of the specialized police stations to represent a real and ethical access to justice.

Keywords: Violence against woman. Ethics. Social justice. Women's special police station.

\section{SUMÁRIO}

1 Introdução. 2 A ética da responsabilidade e a alteridade em Emmanuel Lévinas. 3 A justiça estatal proposta por Nancy Fraser. 4 A delegacia de atendimento à mulher em situação de violência: a (in)eficiência do modelo estatal de acolhimento e proteção. 5 Conclusões. 6 Referências. 


\section{INTRODUÇÃO}

A Constituição Federal de 1988 trouxe a igualdade formal entre homens e mulheres. A década de 90 foi marcada por convenções internacionais referentes aos direitos humanos das mulheres e à erradicação da violência contra a mulher. Os debates sobre gênero e desigualdades na perspectiva do gênero estão em foco permanente no século 21 , tanto no tocante aos direitos das mulheres quanto na identidade de gênero.

A presente pesquisa tem como fundamento os trabalhos normativos e de políticas públicas para combate à violência contra a mulher, tanto no aspecto da punição dos agressores quanto na reestruturação da vida das mulheres em situação de violência. O reconhecimento dos direitos humanos das mulheres não foi capaz de eliminar completamente as desigualdades no campo material; os homens ainda ocupam majoritariamente os espaços públicos (ARENDT, 2007) e o masculino ainda exerce dominação sobre o feminino. Esse contexto privilegia a violência contra a mulher e impede ou dificulta a punição dos agressores, que são, geralmente, seus pais, familiares e companheiros. A situação de submissão e dependência das mulheres faz com que elas se mantenham em relações familiares violentas.

A atuação estatal para a efetivação dos direitos fundamentais das mulheres não é suficiente no campo da igualdade formal. Não basta que o Estado afirme a igualdade de gênero e não realize políticas ou edite leis que discriminem homens e mulheres; é preciso que ele atue afirmativamente para reduzir as igualdades materiais, principalmente em relação à violência contra as mulheres (FRASER, 2006, 2007a). Nesse contexto, precisamos falar de como esse aparato estatal concilia sua efetividade a um ideal de justiça. A partir disso, devemos questionar: Como as mulheres em situação de violência que buscam a tutela estatal são acolhidas? Como o Estado e a sociedade as enxergam? $\mathrm{O}$ atendimento estatal viabiliza o acesso à justiça de mulheres, considerando as dificuldades específicas da mulher no espaço público (ARENDT, 2007)?

Para tanto, analisamos a justiça pela filosofia levinasiana da alteridade e da responsabilidade. A ética em Emmanuel Lévinas está para a relação do Mesmo com o Outro e o terceiro, que demanda justiça, e é essa ética, voltada para a responsabilidade, que qualifica as instituições para a realização do justo. Analisamos também se a justiça em Lévinas relaciona-se intrinsecamente com o Direito e com o Estado e vice-versa. Pelo método do múltiplo dialético (KROHLING, 2014), faremos uma análise histórica e teórica da situação das mulheres até o século 21 , com ênfase no reconhecimento de seus direitos humanos e na luta de sua inclusão nos espaços públicos, bem como estabeleceremos as dificuldades e barreiras peculiares de acesso à justiça das mulheres e a relevância da atuação das delegacias de proteção à mulher para reduzir ou eliminar essas barreiras.

Não obstante ser um Estado Democrático de Direito, formado por uma Constituição democrática e garantista (BRASIL, 1988) e signatário de vários tratados e acordos internacionais para a erradicação da violência de gênero, o Brasil ainda é um país com altos índices de violência contra a mulher. Dados revelam que, apesar da evolução do feminismo e do reconhecimento dos direitos humanos das mulheres, tanto pela comunidade internacional quanto nacional, de 1980 até 2013 morreram 106.093 mulheres nos Estados Brasileiros (WAISELFISZ, 2015). Mesmo depois da entrada em vigor da Lei 11.340/2006 (Lei Maria da Penha), o número 


\section{Humanos e \\ Democracia}

de homicídios de mulheres continuou a crescer numericamente, o que pode nos levar a duas hipóteses: i) a visibilidade dada à violência contra a mulher aumentou o número de denúncias, ampliando o registro estatal; e ii) a lei e as políticas públicas eventualmente instituídas como consequência do aparato legislativo, não foram suficientes para atingir o objetivo de reduzir e erradicar a violência contra a mulher.

Nesse cenário, o Espírito Santo ocupa o 2 o lugar no Mapa da Violência 2015, atrás apenas de Roraima, nos índices de homicídios femininos. A maioria das vítimas mulheres é negra, entre 18 e 30 anos. A domesticidade da violência contra a mulher se revela evidente $-27,1 \%$ dos homicídios femininos aconteceram em casa, enquanto, para os homens, mais da metade dos homicídios se dá em vias públicas (WAISELFISZ, 2015, p 39). Esse dado demonstra que a mulher continua confinada aos espaços privados e subjugada em seu próprio lar, e os homens nos espaços públicos, numa reprodução da teoria arendtiana (ARENDT, 2007). Os parceiros ou ex-parceiros foram nomeados como agressores em mais da metade dos casos de atendimentos a mulheres em situação de violência (WAISELFISZ, 2015).

A mulher em situação de violência sofre agressões sistemáticas - a reincidência é de $54,1 \%$ para atendimentos de casos de violência em mulheres adultas e 60,4\% em mulheres idosas (WAISELFISZ, 2015). Números elevados demonstram que as mulheres estão mais vulneráveis à violência no lar, com seus maridos, companheiros ou namorados, do que nas ruas, espaço social onde as violências masculinas mais comumente ocorrem. Novamente, essa é uma reprodução da teoria arendtiana (ARENDT, 2007), que apresenta a dificuldade que as mulheres têm de transpor a barreira do espaço privado para ocupar os espaços públicos, tradicionalmente dos homens.

Nesse cenário de violência e índices que tiveram redução pouco significativa desde a Constituição Federal de 1988, que positivou direitos fundamentais independente de gênero e igualou formalmente homens e mulheres, o feminino ainda está em posição de desigualdade formal em relação ao masculino. A Lei 11.340/2006 (Lei Maria da Penha) representou marco legislativo com o reconhecimento dos direitos humanos das mulheres no ordenamento jurídico brasileiro e a necessidade da intervenção estatal para a efetivação desses direitos. Considerando a violência contra a mulher um fato a ser erradicado da sociedade brasileira, visto que consiste em violação direta dos direitos humanos, como as mulheres em situação de violência estão sendo acolhidas pelo Estado? Esse acolhimento é suficiente para garantir às mulheres em situação de violência outro direito fundamental: o acesso à justiça ${ }^{1}$

No contexto da violência de gênero, em 1985 foram criadas as primeiras delegacias de proteção à mulher, objetivando oferecer às vítimas de violência um espaço adequado para atendimento de suas queixas e denúncias (PASINATO, 2015). Esse espaço de acolhimento representa o primeiro contato da mulher vítima de violência com o Estado, devendo ser categorizado como vetor de acesso à justiça, que não se resume exclusivamente à judicialização de um conflito. A relevância das delegacias de proteção à mulher para viabilizar o acesso à justiça

\footnotetext{
Utilizamos a expressão "acesso à justiça" na concepção tanto de Mauro Cappelletti (1988), que o considera como acesso ao Poder Judiciário e, ainda, a um provimento judicial justo, capaz de colocar fim ao litígio e atingir a pacificação social, quanto na concepção de Nancy Fraser (2006, 2007a), em que a justiça equivaleria ao reconhecimento da vulnerabilidade da mulher como grupo discriminado historicamente, e à distribuição Estatal para permitir a redução dessa discriminação e a retirada da mulher da situação de vulnerabilidade.
} 
das mulheres em situação de violência, deve ser pontuada como uma ruptura dos espaços públicos exclusivamente masculinos, pensados por homens e para homens. Resta analisar se a instituição cumpre seu papel no atendimento às mulheres que procuram a tutela estatal quando sofrem algum tipo de violência, o que faremos durante este estudo.

\section{A ÉTICA DA RESPONSABILIDADE E A ALTERIDADE EM EMMANUEL LÉVINAS}

Antes da análise proposta, é fundamental uma abordagem sobre a justiça em uma concepção filosófica fundada na ética da alteridade e da responsabilidade de Emmanuel Lévinas e como ela qualifica teoricamente a atuação dos mecanismos estatais que visam a propagar a justiça, funcionando a filosofia levinasiana² como uma espécie de fio condutor entre a ética e a justiça (HADDOCK-LOBO, 2010). Sua filosofia fenomenológica baseia-se em uma crítica à ontologia que subjuga o Outro e à sacralização da razão moderna (DARDEAU, 2013). Dessa forma, poderemos concluir sobre o acesso à justiça proporcionado às mulheres em situação de violência; se ele é ou não compatível com a filosofia ética de Emmanuel Lévinas e se essa (in)compatibilidade afetaria a atuação estatal para a erradicação da violência contra a mulher.

Apesar da influência inicial da fenomenologia husserliana e heideggeriana, Lévinas voltou sua pesquisa para a ética da alteridade e da responsabilidade, afirmando que a responsabilidade pelo Outro precederia a liberdade individual (do Mesmo), sendo indispensável para a convivência humana (KROHLING et al., 2011). Lévinas (2014) propõe um olhar diferente para a ética, situando-o como "filosofia primeira" e matriz de todos os direitos fundamentais. Ele aprofunda os conceitos de Transcendência e o Infinito e os relaciona com a sua reflexão sobre ética.

É importante situar a filosofia levianasiana no contexto em que ela foi desenvolvida - período de Guerras Mundiais, vivência de quatro anos em campo de concentração, genocídios, crise da razão, crise das ciências, desvalorização da vida humana, entre outros. O trabalho de Lévinas aparece para trazer a responsabilidade e a justiça em contraponto à coisificação ontológica (NODARI, 2002). A ética levinasiana da responsabilidade aparece como resposta do apelo da condição humana da época histórica em que ela foi desenvolvida e da experiência pessoal de Lévinas com o Nazismo ${ }^{3}$ e outras agruras da Segunda Guerra Mundial.

Em contraponto à filosofia kantiana, Lévinas coloca a proximidade do Outro para desafiar a individualidade, e sustenta essa relação entre o Mesmo e o Outro como base da alteridade (KROHLING, 2011). O filósofo francês desenvolveu sua teoria com base na filosofia de Martin Buber, para quem "o Eu não é substância, mas relação: existe somente enquanto se refere a um Tu, cuja existência é dada pela palavra que dirige ao Eu" (LÉVINAS, 2014, p. 8). 0 encontro entre Eu e Tu, o falar dele e falar a ele é que permite o acesso à alteridade e possibilita que ela se realize (LÉVINAS, 2014).

\footnotetext{
Emmanuel Lévinas nasceu em Kaunas, na Lituânia, em 1906, e faleceu em 1995. Naturalizou-se Francês em 1939. Estudou filosofia na Universidade de Strasbourg, na França, e foi aluno de Edmund Husserl e Martin Heidegger. Em 1930 publica sua tese intitulada: A Teoria da Intuição na Fenomenologia de Husserl. Entre suas obras estão Existence and Existents (1947), Totalidade e Infinito (1961), Ética e Infinito (1982) e Entre Nós - Ensaios sobre a Alteridade (1991).

3 Emmanuel Lévinas alistou-se no exército francês depois de naturalizado e foi preso em um campo de concentração nazista em 1940. Sua família lituana foi assassinada e sua esposa e filha precisaram ser escondidas em Órleans para escapar.
} 


\section{Humanos e \\ Democracia}

Lévinas acreditava que a ontologia poderia acabar por neutralizar o ser, criticando-a na relação que liga o ser com o objeto do conhecimento. "Nesta ordem, a ontologia aprisiona o ser no campo do conhecimento, e o ser perde sua identidade e sua consistência no entendimento do sujeito cognoscente" (NODARI, 2002, p. 194). Sendo a ontologia uma "filosofia do poder" (NODARI, 2002, p. 195), ela reduziu a alteridade ao indivíduo, ao "eu" ou ao "mesmo". Estando o "eu" no centro do universo, não reconhece nada superior a si e acredita que pode - e deve - ser o destino de todas as coisas. Se o "eu" é autônomo, não faz parte do mundo e tem o mundo como seu objeto, podendo subjugá-lo - e todas as coisas nele presentes, bem como enxerga todas as coisas como se enxergasse a si mesmo (NODARI, 2002). O "outro" não é outro senão o "eu" em si mesmo.

Assim, para a ética como filosofia primeira, "o eu precisa ser destituído de sua pretensa e falsa soberania para que, através da vulnerabilidade, ele aprenda a dizer adeus a este seu mundo tautológico, enclausurado e imutável" (HADDOCK-LOBO, 2010, p. 80). Isso somente seria obtido pelo encontro com o Outro e pela violência sofrida pela transcendência do rosto.

Apesar da inspiração da filosofia de Buber, o encontro Eu-Tu, que pressupõe reciprocidade, difere do encontro do Mesmo com o Outro, que está para a ausência de simetria - o Outro, em sua infinita grandeza, acaba por superar o Mesmo (LÉVINAS, 2014). Esse encontro com o Outro é comunicação e diálogo, colocando a relação ética como o acolhimento do rosto do outro, face a face. Esse rosto não possui referencial no mundo que conhecemos; ele é transcendental, e é essa transcendência que configura o verdadeiro sentido da ética levinasiana. A ausência de tematização do rosto acontece porque a relação com o outro pauta-se no que se quer compreender do outro, porém a compreensão sempre ultrapassa e excede o esperado, tornando sem face o rosto do outro (HADDOCK-LOBO, 2010).

O rosto, para Lévinas, não possui historicidade nem contexto social. Ele não é fenômeno qualquer pois não podemos saber quem é o Outro. $\mathrm{O}$ acolhimento deve acontecer independente da forma como o Outro possa se manifestar. Nesse sentido, posiciona-se:

Tenho descrito sempre o rosto do próximo como portador de uma ordem, que impõe ao eu, diante do outro, uma responsabilidade gratuita - e inalienável, como se o eu fosse escolhido e único - e o outro homem é absolutamente outro, isto é, ainda incomparável e, assim, único. Todavia, os homens que estão à minha volta são tantos! Daí o problema: quem é o meu próximo? Problema inevitável da justiça. Necessidade de comparar os incomparáveis, de conhecer os homens; daí seu aparecer como formas plásticas de figuras visíveis e, de certo modo, "des-figuradas": como um grupo do qual a unicidade do rosto é como que arrancada de um contexto, fonte de minha obrigação diante dos outros homens; fonte à qual a mesma procura da justiça, afinal, de contas, remete e cujo esquecimento arrisca transformar em cálculo meramente político - e chegando até os abusos totalitários - a sublime e difícil obra de justiça (LÉVINAS, 2014, p. 28-29).

Nessa perspectiva da ética, a liberdade e a autonomia do indivíduo são superadas pela responsabilidade e pela alteridade em relação ao Outro que clama pela justiça. Por ser anterior à liberdade, a responsabilidade pelo Outro é transcendência em respeito à subjetividade (LÉVINAS, 1979). É o rosto que revela o apelo à justiça. A liberdade do Mesmo está para a liberdade do Outro, subjugado e dominado. Ao atender a esse apelo, reconhecendo que minha liberdade não é autônoma, o Mesmo se torna justo (LÉVINAS, 2014). 
A relação do Mesmo com o Outro pressupõe a não indiferença à miséria do rosto. 0 acolhimento do Outro requer respeito a esse Outro. Como explica Haddock-Lobo (2010, p. 81), "se se deve acolher o outro como outro, em respeito a sua alteridade, cumpre-se que tal acolhimento deve dar-se independentemente de quaisquer aspectos que este outro possa vir a apresentar". A ética levinasiana, então, pauta-se na superação do Mesmo pelo Outro, no reconhecimento da transcendência do Outro, na linguagem que funda a relação entre o Mesmo e o Outro, na responsabilidade para com o Outro, ciente que o rosto que se desvela não tem forma predefinida. Dessa forma,

O "eu" tem de esquecer seus poderes e reconhecer o outro como nu, despojado, isto é, o "eu" deve rejeitar o livre exercício de sua consciência, acolhendo o outro como pobre e se responsabilizando por ele, não Ihe sendo indiferente. Logo, ao se responsabilizar por outrem, o "eu" acaba por submeter-se ao seu interdito, à sua ordem. Quem acata a ordem reconhece outrem como seu mestre, como seu senhor (PIMENTA, 2010, p. 74).

A filosofia levinasiana também prevê a figura do terceiro, que se colocaria entre a relação do Mesmo com o Outro e que seria para quem se faz a justiça. O terceiro é o próximo e representa o respeito de todos para com todos, uma espécie de responsabilidade coletiva. $\mathrm{A}$ ética da responsabilidade requer o abandono à violência do não reconhecimento, da vingança, da prevalência dos interesses individuais como superiores ao rosto do Outro.

Lévinas não deixou uma teoria voltada para o Direito ou para a justiça legal (estatal), mas não podemos desconsiderar a relação entre justiça estatal e ética, que se mostra pilar deste estudo, em que a ausência de compreensão do Outro conduziria inevitavelmente à injustiça perante este Outro, pela assimilação (e sua consequente aniquilação). O Estado, não pautando a sua justiça em uma ética de responsabilidade e alteridade, ignoraria as diferenças e a pluralidade da sociedade e não conseguiria desenvolver políticas para atingir a desejada igualdade material entre todas as pessoas, uma vez que não saberia reconhecê-las e respeitá-las em suas particularidades.

Concepção interessante da filosofia levinasiana para o presente estudo pauta-se na compreensão de que Lévinas, a priori, materializou o Outro no feminino, assimetria do masculino, o que nos conduz às relações interpessoais que legitimam a violência doméstica pela tentativa de assimilação do Outro feminino pelo eu masculino. Dessa forma, a relação entre homem e mulher deveria afastar-se da falsa ideia de completude pelo risco de o Mesmo assimilar o Outro (LÉVINAS, 1979). O mito do amor romântico esconderia sempre o desejo de assimilação violenta do Outro, do tornar-se-um, o que aniquilaria, assim, a alteridade levinasiana. Assim, a violência contra a mulher, que observamos no cotidiano do século 21, pode ser analisada pela perspectiva de Lévinas a partir do momento em que se apresenta como o filósofo descreveu em suas obras: uma relação de aniquilação do Outro em razão da não compreensão de seu rosto, da insistência em assimilá-lo como eu.

\section{A JUSTIÇA ESTATAL PROPOSTA POR NANCY FRASER}

Filósofa estadunidense, professora da The New School em Nova lorque e pertencente à escola da teoria crítica, Fraser elaborou uma teoria que conjuga três requisitos para a propagação da justiça. Ressaltamos aqui que Fraser, diferentemente de Lévinas, desenvolve uma teoria focada na atuação estatal, mas que pode ser qualificada pela filosofia levinasiana, 


\section{Humanos e \\ Democracia}

principalmente para o presente estudo. Para ela, há uma deficiência em teorias da justiça meramente distributivas ou em teorias do reconhecimento, como as de Charles Taylor e Axel Honneth, pois elas abrangem apenas um aspecto dos clamores sociais contemporâneos (FRASER, 2007a). Ainda, Fraser (2007a) destaca que é necessário garantir a participação dos grupos minoritários na elaboração das leis e das políticas públicas para que esses grupos, tendo voz efetiva, possam ser nelas representados.

Para entender a teoria frasiana, devemos primeiro compreender que os diferentes grupos e indivíduos podem estar segregados ou discriminados de distintas maneiras na sociedade, o que torna seus pleitos diferentes. As demandas dos grupos LGBTs, dos grupos étnicos, dos grupos religiosos e do feminismo, são diversas, mesmo que, ao final, tenham o mesmo objetivo: oportunidades e reconhecimento. Se as demandas são diferentes e os graus de discriminação sofrida por esses grupos são diversas, nem todas essas demandas poderão ser atendidas da mesma forma.

Fraser (2006) entende que a distribuição, como critério de justiça, tem uma conotação de equalização econômica, ou seja, pretende igualar os grupos em desvantagem econômica para que todos possam ter as mesmas oportunidades reais, e atenderia aos grupos que não conseguem ascender financeiramente por estarem inseridos em uma zona de pobreza que Ihes impede disputar igualitariamente os espaços no mercado econômico.

Políticas sociais, como o Bolsa Família, são, geralmente, fruto das teorias distributivas, pois funcionam como mecanismos para regular uma sociedade economicamente desigual. Assim, pessoas sem oportunidades e sem acesso a bens primários para garantir-lhes a sobrevivência - o que, para Amartya Sen (2011), é uma das maiores injustiças do mundo -, receberiam auxílio do Estado para atingirem uma igualdade material e, assim, poderem concorrer com outros grupos socialmente privilegiados.

Já o reconhecimento não visa a equalizar indivíduos e grupos; ao contrário. A premissa das teorias do reconhecimento é o reforço às diferenças para garantir a todos o direito à identidade. Axel Honneth (2003) entende que o reconhecimento se dá em três estágios, sendo eles o autorreconhecimento, o reconhecimento jurídico (pelo Estado) e o reconhecimento social. O desrespeito à identidade de pessoas e grupos é, por si, uma situação de injustiça que precisa ser tratada.

Enquanto a distribuição visa a eliminar as diferenças, o reconhecimento objetiva reforçá-las e empoderá-las. Para Fraser (2007a), nenhuma delas, isoladamente, é capaz de atender às demandas por justiça das sociedades contemporâneas, principalmente porque há grupos que se encontram em uma zona nebulosa e pouco distinguível de seus pleitos, pois eles se revestem de características distributivas e identitárias.

Esse seria o caso dos grupos étnicos, que desejam tanto a igualdade de oportunidades no mercado com a erradicação do racismo (todas as raças são iguais), mas também anseiam pelo reconhecimento de sua identidade como grupo e, consequentemente, a afirmação e elevação de suas diferenças. Nesse mesmo contexto temos as mulheres como gênero, que pleiteiam a sua inserção nos espaços públicos tradicionalmente masculinos com a erradicação das desigualdades entre gêneros (homens e mulheres são iguais), mas também desejam a manutenção de suas identidades femininas (FRASER; HONNETH, 2003). 
Para Fraser, é impossível que o Estado lide com tais pleitos utilizando-se apenas das teorias distributivas ou de reconhecimento. Fraser identifica que apenas uma conjugação entre essas teorias seria capaz de atender aos grupos dessa zona de indistinção, o que levaria a uma concepção de justiça com mais de uma dimensão.

É importante esclarecer que Nancy Fraser, em seus primeiros trabalhos, considerava uma justiça bidimensional, ou seja, que teria um aspecto distributivo e outro de reconhecimento identitário. Em suas obras mais recentes, Fraser considerou um terceiro elemento em sua teoria da justiça: a participação política paritária. Dessa forma, seria inefetiva uma teoria que não englobasse a representatividade de todos os grupos sociais, principalmente os minoritários. Sem voz política, as leis e ações estatais continuariam a ser elaboradas pelas maiorias, em uma visão "de cima para baixo" das necessidades dos grupos minoritários.

Dessa forma, as injustiças somente seriam erradicadas se, além da distribuição de recursos e o respeito às identidades, as minorias também pudessem ter representatividade, conferida pela participação política (FRASER; HONNETH, 2003).

Considerando esta teoria sobre a atuação justa do Estado, cabe analisar se as políticas sociais e afirmativas brasileiras condizem com a tridimensionalidade esperada por Nancy Fraser, mais especificamente no tocante ao reconhecimento identitário. Seriam essas políticas suficientes e eficientes para garantir tanto a distribuição quanto o reconhecimento? E, em se observando uma resposta negativa, faltaria a essas políticas a representatividade adequada para que as minorias pudessem manifestar seu clamor por reconhecimento?

\section{A DELEGACIA DE ATENDIMENTO À MULHER EM SITUAÇÃO DE VIOLÊNCIA: A (In)Eficiência do Modelo Estatal de Acolhimento E Proteção}

Em um primeiro momento, consideramos necessário justificar o termo "mulher em situação de violência" utilizado neste estudo, em substituição ao tradicional "mulher vítima de violência". A violência de gênero foi reconhecida, pela comunidade internacional, como um fenômeno cultural e social e, portanto, sugere que as mulheres se encontram sujeitas à violência por sua condição feminina, não são vítimas de violência aleatória ou descaracterizadas de fundamentos culturais (PASINATO, 2015). Trata-se, portanto, de fenômeno que deve ser combatido com políticas públicas específicas, uma vez que o entendimento de que o combate à violência, de modo geral, não é suficiente para que as mulheres deixem de sofrer violência de gênero.

Em um segundo momento, demonstraremos nesse tópico como atuam as delegacias especializadas para atendimento a essas mulheres em situação de violência, incluindo uma breve análise do modelo desenvolvido pelo Estado de atenção à mulher, conforme estabelecido na Lei 11.340/2006, e relacionaremos esse atendimento à justiça frasiana e à filosofia levinasiana, que se mostrarão como fios condutores da atuação estatal justa e igualitária.

Em 1983, Maria da Penha Maia Fernandes, mulher, foi vítima de violência doméstica cometida por seu marido, que tentou matá-la em duas ocasiões: por meio de arma de fogo, causando lesões que a deixaram paraplégica, e por meio de eletrocussão durante o banho. Em 1998, Maria da Penha foi à Corte Interamericana de Direitos Humanos (CIDH) contar sua história e pedir que providências fossem tomadas em relação à tolerância para com a violên- 


\section{Humanos e \\ Democracia}

cia cometida contra ela. O Estado Brasileiro deixou de apresentar as manifestações solicitadas tanto em 2000 quanto em 2001, quando Ihe foi enviado o relatório da CIDH. Dessa forma, o relatório foi tornado público e levado à Assembleia Geral da OEA. ${ }^{4}$

A violência sofrida por Maria da Penha, vítima das agressões do próprio marido, não é um caso isolado. As mulheres brasileiras são manchetes diárias como vítimas de homicídio, tentativa de homicídio, lesão corporal de leve a gravíssima e outros casos envolvendo também a violência psicológica, todas causadas por companheiros, ex-companheiros ou pessoas próximas, em quem elas deveriam confiar. O Brasil, internacionalmente conhecido como violador de tratados internacionais de proteção e combate da violência contra a mulher, apenas em 2006 passou a ter uma legislação voltada para a temática, reconhecendo a especificidade da violência de gênero.

A Lei 11.340/2006 recebeu o nome de Lei Maria da Penha em homenagem à mulher que levou a âmbitos internacionais a discussão da ineficácia do Estado em prevenir, combater, erradicar a violência contra a mulher. Essa foi a primeira norma brasileira a reconhecer os direitos humanos das mulheres (artigo 2ํ), não obstante o Brasil tenha sido signatário de tratados internacionais com o mesmo objetivo: a Convenção sobre a Eliminação de Todas as Formas de Discriminação contra as Mulheres, aprovada pela Assembleia Geral da ONU em 1979 e ratificada pelo Brasil sem ressalvas em 1994, e a Convenção para Prevenir, Punir e Erradicar a Violência contra a Mulher, também denominada "Convenção de Belém do Pará", aprovada pela Organização dos Estados Americanos em 1994, dois exemplos de documentos internacionais comprometidos com o fim da violência contra a mulher.

Apesar de a Lei 11.340/2006 ser reconhecida como a mais relevante sobre violência contra a mulher no Brasil, ela não é protagonista no tema. A atuação estatal para atender às especificidades da violência de gênero não corresponde a um pacote coerente e sequencial de políticas públicas para atingir a finalidade de eliminar a violência contra a mulher. Ao invés de um projeto complexo e multidisciplinar para a obtenção do fim desejado, o Estado brasileiro agiu, até então, de forma difusa, posto que os mecanismos desenvolvidos não foram executados em congruência à base teórica que os originou.

O presente trabalho apresenta foco na estruturação e atuação das delegacias especializadas em atendimento às mulheres em situação de violência, delimitando, assim, seu objeto de estudo. Essas delegacias não foram instituídas pela Lei 11.340/2006, e a primeira foi instalada em São Paulo no ano de 1985 por Michel Temer, à época secretário de Segurança no mandato do governador André Franco Montoro. A Secretaria Especial de Políticas para Mulheres, do governo federal, e a Secretaria Nacional de Segurança Pública do Ministério da Justiça, elaboraram, em 2006, uma cartilha a fim de estabelecer normas para o funcionamento das Delegacias da Mulher, denominadas Delegacias de Atendimento à Mulher (DEAM). 0 texto da cartilha apresenta a justificativa da criação das delegacias especializadas e sua solidão como política única de proteção à mulher:

\footnotetext{
4 Informações do Relatório da Comissão Interamericana de Direitos Humanos 54/01, Caso 12.051, de 4 de abril de 2001. Disponível em: http://www.cidh.org/annualrep/2000port/12051.htm.
} 
As DEAMs foram uma experiência pioneira, genuinamente brasileira desde sua criação e contribuíram para dar visibilidade ao problema da violência contra a mulher, especialmente aquela ocorrida no ambiente doméstico, no interior das relações conjugais e familiares, para o reconhecimento, pela sociedade, da natureza criminosa da violência baseada em diferenças de gênero, a qual a mulher estava submetida; e permitiu a institucionalização da política pública de prevenção, enfrentamento e erradicação da violência contra a mulher no Brasil. No entanto, uma vez que as DEAMs se constituíam como a única política pública governamental voltada para coibir a violência doméstica e sexual, estes equipamentos acabaram por realizar atividades não decorrentes da ação policial com vistas a atender uma demanda que até então encontrava-se reprimida (BRASIL, 2006).

Atualmente, o Brasil possui uma delegacia a cada 12 municípios nacionais, o que representa um total de 499 unidades especializadas em 447 cidades (ANDRADE, 2016). Esses números, de per si, já demonstram aparente insuficiência para a demanda e para que se atinja a finalidade das delegacias especializadas, que foram criadas com o objetivo de proporcionar um acolhimento imediato adequado às mulheres em situação de violência (PASINATO, 2004). Ainda, as delegacias especializadas atendiam crianças e adolescentes, pessoas idosas, homossexuais e outra vítimas de violências diversas, para as quais já existem - ou deveriam existir - políticas públicas específicas de atendimento (BRASIL, 2006).

Pressupõe-se, dessa forma, que a delegacia tradicional não é estruturada de modo a atender à mulher em situação de violência - ela é elaborada por homens, para homens, pois as mulheres sequer deveriam ocupar tais espaços (ARENDT, 2007; OKIN, 2013). As mulheres, na concepção da sociedade patriarcal, devem manter-se nos espaços privados e submeter-se aos seus maridos e companheiros, o que levaria à não necessidade de criação de estruturas adequadas para recebê-las na vida pública.

Apesar de a violência de gênero ser mais frequente nos espaços privados (WAIZELFISZ, 2015), a mulher não deveria, pela lógica heteronormativa do patriarcado, sequer denunciar eventuais agressões de seu marido ou companheiro. Ao se abandonar essa lógica e reconhecer a igualdade entre gêneros e a condição específica da violência de gênero, a criação das delegacias de proteção à mulher se torna necessária para atender à vítima dessa violência, que está em estado de absoluta vulnerabilidade.

Podemos, nesse momento, estabelecer um paralelo entre a ética da responsabilidade levinasiana e a atuação das delegacias especializadas. A mulher, na posição de quem demanda justiça, precisa ser acolhida, cuidada, respeitada como o Outro, independente da forma assumida por seu rosto. A justiça para a mulher em situação de violência somente será justa se reconhecer sua vulnerabilidade - não há justiça sem ética.

A carência de unidades de delegacia especializadas demonstra que nem todas as muIheres brasileiras terão acesso a um atendimento que respeite as especificidades da violência de gênero, sendo compelidas a buscar as delegacias tradicionais, não estruturadas para atender mulheres em situação de violência pela não esperada sensibilidade daqueles que deverão receber e acolher as vítimas.

As características do atendimento dos agentes estatais para as mulheres em situação de violência vêm descrita na própria cartilha que orienta a estruturação das delegacias especializadas: 


\section{Humanos e \\ Democracia}

É importante ressaltar que as mulheres em situação de violência de gênero devem ser consideradas como sujeito de direitos e merecedoras de atenção. Os policiais envolvidos no atendimento a essas mulheres devem ter escuta atenta, profissional e observadora, de forma a propiciar o rompimento do silêncio, do isolamento destas mulheres e, em especial, dos atos de violência, aos quais estão submetidas (BRASIL, 2006).

Dessa forma, observa-se que as delegacias para atendimento da mulher devem contar com profissionais sensibilizados para a situação da violência de gênero e suas especificidades, principalmente no tocante ao contexto sociocultural das vítimas, no caráter reincidente da violência e na dependência econômica das mulheres que, muitas vezes, levam à manutenção da submissão a seus companheiros e maridos.

Maior gravidade percebe-se, então, quando a delegacia especializada existe, porém não cumpre com sua função - não acolhe, não demonstra cuidado nem responsabilidade para com o Outro. Relatos de mulheres que buscaram atendimento nas delegacias de proteção à mulher indicam que estas são desestimuladas a prosseguir com a denúncia contra seus maridos ou companheiros e que são frequentemente revitimizadas. Em pesquisa realizada nas delegacias especializadas brasileiras, a jornalista Helena Bertho (2016) levantou que não existe treinamento especializado para os policiais que atuam em casos de violência de gênero; apenas uma disciplina de direitos humanos, o que não representa sensibilização específica para a questão da violência doméstica.

Wania Pasinato (2015) considera que essa situação se escora em padrões culturais que naturalizam a violência doméstica e a tratam como questão privada, que deve ser resolvida, quando possível, entre o casal. A culpabilização da vítima de violência de gênero, recorrente na aplicação da Lei 11.304/2006, também dificulta o pleno atendimento pelos agentes estatais, que devem acolher e aplicar as políticas públicas a fim de prevenir e reprimir a violência doméstica.

Esse problema é relatado pela ativista feminista Clara Averbuck, em texto publicado na revista Carta Capital, narrando as dificuldades que vivenciou, juntamente com uma amiga, para denunciar uma agressão doméstica. As duas mulheres foram obrigadas a esperar por mais de uma hora para serem atendidas e tiveram de voltar no dia seguinte, além de terem presenciado ofensas de agentes estatais para com as vítimas, culpabilização das vítimas e descaso na tomada dos depoimentos (AVERBUCK, 2015).

Também não existe plantão noturno ou aos finais de semana em grande parte das delegacias especializadas. Em Vitória - Espírito Santo -, apenas uma delegacia de proteção à muIher funciona aos finais de semana e à noite, e vítimas de violência sem flagrante devem para lá se dirigir. Na delegacia, que conta com atendentes do sexo masculino, os depoimentos são tomados na recepção (BERTHO, 2016). O mesmo acontece com outros Estados, e apenas no Rio de Janeiro todas as delegacias especializadas funcionam 24 horas por dia (BERTHO, 2016).

Essa situação de desamparo da vítima de violência familiar que procura atendimento estatal, também foi mostrada em matéria realizada pela BBC Brasil (MENDONÇA, 2015). MuIheres que buscam a delegacia especializada são desestimuladas a denunciar as agressões sofridas por agentes estatais que tratam a situação como mera intransigência da mulher. Uma 
vítima de violência ${ }^{5}$ acabou desistindo de denunciar a violência sofrida em razão da atitude do delegado que a atendeu. Na sequência são expostas algumas frases imputadas à autoridade estatal no momento do atendimento:

Você tem certeza que vai fazer isso (denunciar)? Essas marcas aí? Estão tão fraquinhas... até você chegar no IML (para fazer exame de corpo de delito), já vão ter desaparecido. Se você denunciar, vai acabar com a vida dele. Ele vai perder o emprego e não vai adiantar nada, porque vai ficar alguns dias preso, depois vai pagar fiança e vai sair ainda mais bravo com você (MENDONÇA, 2015).

Quando a mulher procura a delegacia especializada para denunciar agressões domésticas ou crimes sexuais, também é revitimizada e culpabilizada. Seu discurso é comumente desacreditado e precisa oferecer provas contundentes de que não está mentindo - marcas de agressão não são consideradas suficientes e muitas são levadas a acreditar que a denúncia "não vai dar em nada" (MENDONÇA, 2015). Alguns casos de violência contra a mulher também deixam de ser atendidos pela delegacia especializada e acabam sendo direcionados a órgãos ainda menos sensíveis e preparados para atendê-los. Podemos exemplificar com a problemática envolvendo a denúncia de estupro coletivo por uma jovem de 16 anos, ocorrido em maio de 2016, que foi inicialmente dirigido à Delegacia de Repressão aos Crimes de Informática. A jovem foi atendida por um delegado (sexo masculino) que, posteriormente, foi afastado do caso por ter demonstrado não acreditar no relato da vítima porque ela seria envolvida com o tráfico de drogas e por ter feito perguntas ofensivas (MARTINS, 2016).

A violência contra a mulher não diminuiu depois da criação das delegacias especializadas ou outros mecanismos de combate à violência de gênero, tampouco após a Lei 11.340/2006. É o que apresenta o Mapa da Violência de 2015: entre 1980 e 2013, o número de homicídios de mulheres cresceu 252\% (WAIZELFISZ, 2015). Isso significa que esses mecanismos, incluindo-se a delegacia de atendimento à mulher, que acaba por ser responsável pelo primeiro contato da vítima de violência de gênero com o aparato estatal que deveria protegê-la e ampará-la, não estão sendo executados adequadamente ou não são adequados ao seu fim. Considerando que essa é uma questão mais ampla e que foge parcialmente do objeto desta pesquisa, mesmo assim devemos considerar que a ineficiência não é exclusivamente numérica.Pesquisa realizada pelo DataSenado concluiu, em 2013, que pelo menos $15 \%$ das mulheres que sofreram agressões domésticas não procuraram qualquer ajuda ou denunciaram seus agressores, enquanto pelo menos $34 \%$ dessas mulheres buscou ajuda informal, com familiares e amigos. A mesma pesquisa levantou que $74 \%$ das mulheres entrevistadas expuseram que o medo do agressor era motivo principal para a não denunciação da violência doméstica, porém $23 \%$ alegou que acreditam não haver punição para o agressor e $19 \%$ acreditam que a mulher em situação de violência não conhece seus direitos (BRASIL, 2013).

A matéria da BBC Brasil preservou a identidade das mulheres entrevistadas utilizando-se de nomes fictícios. A vítima em questão foi nomeada Maria Fernanda. 


\section{Humanos e \\ Democracia}

\section{CONCLUSÕES}

A pesquisa propôs analisar as delegacias da mulher em uma perspectiva de acesso à justiça. Uma justiça pautada na ética e atuação estatal positiva, à luz das teorias da justiça filosófica em Emmanuel Lévinas e teoria da justiça como distribuição e reconhecimento em Nancy Fraser. Nesse sentido, a delegacia da mulher apareceria como aparato estatal destinado a proporcionar às mulheres em situação de violência atendimento - e esse atendimento deve ser sempre ético.

Foram observadas, no entanto, deficiências numéricas e estruturais nas delegacias de proteção à mulher que perduram desde a sua criação, em 1985. Atualmente, há pouco mais de 400 unidades espalhadas em mais de 5,5 mil municípios, o que demonstra ausência do serviço especializado e sugere ineficiência no acesso a esse atendimento primeiro à mulher em situação de violência. Estruturalmente, há também vícios relacionados à falta de preparo dos agentes estatais que lidam com a violência doméstica e sexual contra mulheres, falta de empatia e acolhimento, deficiência de pessoal, delegacias mal localizadas e com instalações precárias, entre outros.

Essas deficiências na distribuição, atribuição e atendimento nas delegacias especializadas levam a deficiências na própria atuação estatal voltada para a mulher em situação de violência. Essa mulher, reconhecidamente para quem a lei se faz (HADDOCK-LOBO, 2010), que precisa de cuidado e amparo em sua vulnerabilidade, tem sua condição especial assumida pelo Estado, mas não consegue respeito no tratamento pelos agentes prepostos deste Estado.

As delegacias especializadas devem estruturar-se conforme preceitos da justiça filosófica levinasiana e justiça tridimensional de Nancy Fraser. Nessa perspectiva, atenderiam, mais eficientemente, aos propósitos dos tratados internacionais ratificados pelo Brasil e da própria Lei Maria da Penha, que reconhecem a mulher como sujeito de direitos humanos e as especificidades da violência de gênero. Assim, é preciso repensar a dinâmica estrutural desse mecanismo estatal para perseguição de um acesso à justiça pleno.

Pela ética levinasiana, as delegacias de proteção à mulher deveriam pautar-se em um atendimento ético e de alteridade para com as vítimas que procuram auxílio estatal. Devem ser espaços de responsabilidade para com o Outro, onde a mulher possa ser acolhida e respeitada na situação de crise, no seu clamor por justiça. A necessidade de sensibilização dos agentes estatais para a justiça ética, para que pautem seu fazer na alteridade e no respeito ao seu próximo, é pungente.

No mesmo sentido, as delegacias especializadas não podem ser entendidas como medida singular de proteção às mulheres em situação de violência. O viés exclusivamente punitivo das políticas públicas voltadas para a erradicação da violência doméstica e sexual contra muIheres, ignora a construção cultural da violência de gênero (BEAUVOIR, 2009; OKIN, 2013) e sugere que apenas a imposição de um procedimento penal mais rigoroso terá papel pedagógico na reeducação dos agressores - o que se mostra falso pelo aumento constante e gradativo da violência contra a mulher.

Nessa visada, tem-se a teoria frasiana que propõe uma atuação tridimensional do Estado para a promoção de justiça para minorias. A necessidade de medidas que visem à distribuição (viés econômico), reconhecimento (viés cultural) e representatividade (viés político), 
se mostra específica em casos de violência de gênero, pois as mulheres sofrem violência em razão de práticas culturais sustentadas pela sociedade patriarcal e, com isso, estão alijadas do processo produtivo-econômico e dos espaços públicos. A garantia estatal de medidas educativas e que permitam às mulheres em situação de violência a fuga da dependência econômica de seus companheiros, coloca em xeque a eficiência de mecanismos unidimensionais - ou seja, a delegacia da mulher somente será eficiente se atuar em conjunto com uma série de medidas públicas voltadas para o fim da cultura que subjuga a mulher.

\section{REFERÊNCIAS}

ANDRADE, H. Brasil tem uma delegacia com atendimento à mulher a cada 12 municípios. UOL Notícias. 2016. Disponível em: http://noticias.uol.com.br/cotidiano/ultimas-noticias/2016/06/05/brasil-tem-uma-delegaciacom-atendimento-a-mulher-a-cada-12-municipios.htm.

ARENDT, H. A condição humana. 10. ed. Rio de Janeiro: Forense Universitária, 2007.

ARISTÓTELES. Ética a nicômaco. 4. ed. São Paulo: Martin Claret, 2010.

AVERBUCK. C. A ineficiência da delegacia da mulher. Revista Carta Capital - Escritório Feminista, 28 mar. 2015. Disponível em: http://www.cartacapital.com.br/blogs/escritorio-feminista/a-ineficiencia-da-delegacia-damulher-1964.html.

BEAUVOIR, S. O segundo sexo. Versão digital. 2. ed. Rio de Janeiro: Nova Fronteira, 2009.

BERTHO, H. Quando a delegacia é uma nova violência. Revista AzMina, 31 out. 2016. Disponível em: http://azmina.com.br/2016/10/quando-a-delegacia-e-uma-nova-violencia.

BRASIL. Constituição da República Federativa do Brasil de 1988. 1988 . Disponível em: http://www.planalto.gov.br/ccivil_03/constituicao/constituicaocompilado.htm. Acesso em: 2 dez. 2016.

BRASIL. Lei 11.340 de 07 de agosto de 2006. Cria mecanismos para coibir a violência doméstica e familiar contra a mulher, nos termos do $\S 80$ do art. 226 da Constituição Federal, da Convenção sobre a Eliminação de Todas as Formas de Discriminação contra as Mulheres e da Convenção Interamericana para Prevenir, Punir e Erradicar a Violência contra a Mulher; dispõe sobre a criação dos Juizados de Violência Doméstica e Familiar contra a Mulher; altera o Código de Processo Penal, o Código Penal e a Lei de Execução Penal; e dá outras providências. Disponível em: https://www.planalto.gov.br/ccivil_03/_Ato2004-2006/2006/Lei/L11340.htm. Acesso em: 2 dez. 2016.

BRASIL. Senado Federal. DataSenado. A violência doméstica e familiar contra a mulher. 2013. Disponível em: https://www12.senado.leg.br/institucional/datasenado/publicacaodatasenado?id=a-violencia-domesticacontra-a-mulher. Acesso em: 2 dez. 2016.

DARDEAU, D. Aporias da justiça - entre Lévinas e Derrida. Sapere Aude, Belo Horizonte, v. 4, n. 7, 2013.

FRASER, N. Mapeando a imaginação feminista: da redistribuição ao reconhecimento e à representação. Estudos Feministas, Florianópolis, n. 15(2), p. 240, maio/ago. 2007a.

FRASER. N. Reconhecimento sem ética? Lua Nova, São Paulo, n. 70, p. 101-138, 2007b.

FRASER, N. Da redistribuição ao reconhecimento? Dilemas da justiça numa era "pós-socialista". Cadernos de Campo, São Paulo, n. 14/15, p. 231-239, 2006.

FRASER, N.; HONNETH, A. Recognition or Redistribution? A political-philosophical exchange. Londres: Verso, 2003.

HADDOCK-LOBO, R. A justiça e o rosto do outro em Lévinas. Cadernos da Emarf - Fenomenologia do Direito, Rio de Janeiro, v. 3, n. 1. abr./set. 2010.

HONNETH, A. Luta por reconhecimento: a gramática moral dos conflitos sociais. São Paulo: Editora 34, 2003.

KROHLING, A et al. A ética da responsabilidade pela dignidade da pessoa humana: em busca da superação da neutralidade e da objetividade no direito. Direitos Fundamentais \& Justiça, Porto Alegre, ano 5, n. 14, 2011.

KROHLING, A. A ética da alteridade e da responsabilidade. Curitiba: Juruá, 2011.

KROHLING, A. Dialética e direitos humanos: múltiplo dialético - da Grécia à contemporaneidade. Curitiba: Juruá, 2014.

LÉVINAS, E. Totality and Inifinity - An essay on exteriority. Boston: Martinus Nijhoff Publishers, 1979. 


\section{Humanos e \\ Democracia}

LÉVINAS, E. Violência do rosto. São Paulo: Edições Loyola, 2014.

MARTINS, M. A. Polícia afasta delegado que primeiro investigou estupro de adolescente. Folha de São Paulo, 2 jun. 2016. Disponível em: http://www1.folha.uol.com.br/cotidiano/2016/06/1779366-policia-afasta-delegadoque-primeiro-investigou-estupro-de-adolescente.shtml. Acesso em: 2 dez. 2016.

MENDONÇA, R. Violência doméstica: 5 obstáculos que mulheres enfrentam para denunciar. BBC Brasil, 10 dez. 2015. Disponível

http://www.bbc.com/portuguese/noticias/2015/12/151209_obstaculos_violencia_mulher_rm. Acesso em: 2 dez. 2016.

MIYAMOTO, Y. M. H.; KROHLING, A. Cidadania no estado democrático de direito sob a perspectiva de gênero. CONGRESSO NACIONAL DO CONPEDI, 21., Niterói: UFF, 2012.

MIYAMOTO, Y. M. H.; KROHLING, A. Sistema prisional brasileiro sob a perspectiva de gênero: invisibilidade e desigualdade social da mulher encarcerada. Direito, Estado e Sociedade, n. 40, p. 223-241, jan./jun. 2012.

NODARI, P. C. O rosto como apelo à responsabilidade e à justiça em Lévinas. Síntese - Revista de Filosofia, Belo Horizonte, v. 29, n. 94, 2002.

ORGANIZAÇÃO DOS ESTADOS AMERICANOS. Comissão Interamericana de Direitos Humanos. Relatório Anual 2000. Relatório 54/01. Caso 12.051. Maria da Penha Maia Fernandes - Brasil. Disponível em: http://www.cidh.org/annualrep/2000port/12051.htm. Acesso em: 24 nov. 2016.

OKIN, S. M. Women in westernet political thought. Versão digital. New Jersey: Princeton University Press, 2013.

PASINATO, W. Violência contra a mulher no Brasil: acesso à justiça e construção da cidadania de gênero. CONGRESSO LUSO-AFRO-BRASILEIRO DE CIÊNCIAS SOCIAIS, 8., Coimbra, 2004.

PASINATO, W. Acesso à justiça e violência doméstica e familiar contra as mulheres: as percepções, os operadores jurídicos e os limites para a aplicação da Lei Maria da Penha. Revista Direito GV, n. 11(2), p. 407-428, jul./dez. 2015.

PIMENTA, L. G. Justiça, alteridade e Direitos Humanos na teoria de Emmanuel Lévinas. Revista Direito e Humanidades, São Caetano do Sul, ano XI, n. 19, jul./dez. 2010.

RAWLS, John. Uma teoria da justiça. São Paulo: Martins Fontes, 1997.

SAFFIOTI, H. I. B. Contribuições feministas para o estudo da violência de gênero. Cadernos Pagu, n. 16, p. 115136, 2001.

SAFFIOTI, H. I. B. Violência de gênero: o lugar da práxis na construção da subjetividade. Revista Lutas Sociais, São Paulo: Pontifícia Universidade Católica, n. 2, p. 59-79, 1997.

SEN, Amartya. A ideia de justiça [versão Kindle]. São Paulo: Companhia das Letras, 2011.

STANFORD ENCYCLOPEDIA OF PHILOSOPHY. Emmanuel Lévinas. Disponível em: http://plato.stanford.edu/entries/levinas/. Acesso em: 23 nov. 2016.

WAISELFISZ, J. J. Mapa da violência 2015 - homicídio de mulheres no Brasil [on-line]. 1 ed. Brasília, 2015. Disponível em: http://www.mapadaviolencia.org.br. Acesso em: 23 jun. 2016. 